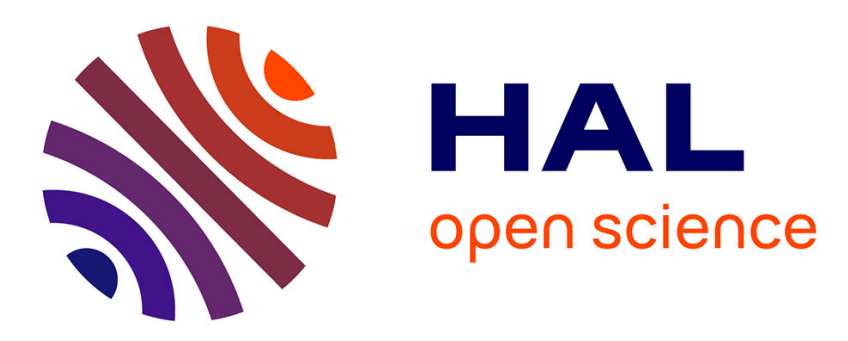

\title{
How vial geometry variability influences heat transfer and product temperature during freeze-drying
}

Bernadette Scutella, Stéphanie Passot, Erwan Bourlés, Fernanda Fonseca, Ioan-Cristian Trelea

\section{To cite this version:}

Bernadette Scutella, Stéphanie Passot, Erwan Bourlés, Fernanda Fonseca, Ioan-Cristian Trelea. How vial geometry variability influences heat transfer and product temperature during freeze-drying. Journal of Pharmaceutical Sciences, 2017, 106 (3), pp.770-778. 10.1016/j.xphs.2016.11.007 . hal01465155

\section{HAL Id: hal-01465155 \\ https://hal.science/hal-01465155}

Submitted on 10 Feb 2017

HAL is a multi-disciplinary open access archive for the deposit and dissemination of scientific research documents, whether they are published or not. The documents may come from teaching and research institutions in France or abroad, or from public or private research centers.
L'archive ouverte pluridisciplinaire HAL, est destinée au dépôt et à la diffusion de documents scientifiques de niveau recherche, publiés ou non, émanant des établissements d'enseignement et de recherche français ou étrangers, des laboratoires publics ou privés. 
4 Authors: BERNADETTE SCUTELLA ${ }^{1,2}$, STEPHANIE PASSOT $^{1}$, ERWAN BOURLES ${ }^{2}$, 5 FERNANDA FONSECA ${ }^{1}$, IOAN CRISTIAN TRELEA ${ }^{1}$

6

$7{ }^{1}$ UMR GMPA, AgroParisTech, INRA, Université Paris Saclay, 78850 Thiverval-Grignon, 8 France

$9 \quad{ }^{2}$ GSK Vaccines, Rixensart, Belgium 
11 ABSTRACT: Vial design features can play a significant role in heat transfer between the 12 shelf and the product and, consequently, in the final quality of the freeze-dried product. Our objective was to investigate the impact of the variability of some geometrical dimensions of a set of tubing vials commonly used for vaccine production on the distribution of the vial heat transfer coefficients $\left(K_{v}\right)$ and its potential consequence on product temperature. Sublimation tests were carried out using pure water and eight combinations of chamber pressure (4 to 50 $\mathrm{Pa})$ and shelf temperature $\left(-40{ }^{\circ} \mathrm{C}\right.$ and $\left.0{ }^{\circ} \mathrm{C}\right)$ in two freeze-dryers. $K_{v}$ values were individually determined for 120 vials located in the center of the shelf. Vial bottom curvature depth and contact area between the vial and the shelf were carefully measured for 120 vials and these data were used to calculate $K_{v}$ distribution due to variability in vial geometry. At low pressures commonly used for sensitive products (below $10 \mathrm{~Pa}$ ), the vial-shelf contact area appeared crucial for explaining $K_{v}$ heterogeneity and was found to generate, in our study, a product temperature distribution of approximately $2{ }^{\circ} \mathrm{C}$ during sublimation. Our approach provides quantitative guidelines for defining vial geometry tolerance specifications and product temperature safety margins.

Keywords: Freeze drying/lyophilization; amorphous; drying; vaccines; distribution; vial heat transfer coefficient; sublimation rate; vial design; inter-vial heterogeneity 
Nowadays, freeze-drying is an essential and valuable preservation method to ensure the longterm stability of the growing list of biopharmaceuticals such as antibodies, hormones, vaccines, therapeutics peptides and proteins. This method makes it possible to remove the majority of water at temperatures far below $0{ }^{\circ} \mathrm{C}$ (usually between $-40{ }^{\circ} \mathrm{C}$ and $-20{ }^{\circ} \mathrm{C}$ ) by sublimation, the phase transition from ice to water vapor. ${ }^{1}$

Due to the really low temperature and pressure typically used, freeze-drying remains a time consuming process often difficult to control and scale-up. The US Food and Drug Administration has recently proposed a new regulatory philosophy to manage product quality: the Quality by Design (QbD) initiative. Quality will be no more tested into the product but designed into the process. The $\mathrm{QbD}$ approach is based on pre-defined quality targets and on a deep understanding of how formulations and process interact to influence critical quality attributes of pharmaceutical products. ${ }^{2}$ In contrast to tablets, products intended to be freeze-dried are conditioned in their final packaging system (vial or syringe) before the process. ${ }^{3}$ The vial thus directly influences the freeze-drying process and impacts final product quality. ${ }^{4,5}$ Furthermore, since the capacity of a manufacturing freeze-dryer can easily reach 100000 vials, ensuring uniform product quality attributes (potency of the active ingredient, residual moisture content, visual aspect of the freeze-dried cake) within the entire batch represents a real challenge. Any variation in the design of the packaging system or other parameters could result in product quality variation.

52 Product temperature is a key process parameter governing an important critical product quality attribute, the visual aspect of the freeze-dried cake, which in turn could influence the residual moisture, the stability of the active ingredient and the reconstitution time. ${ }^{6}$ During the process the product temperature should be maintained below a critical value corresponding to the glass transition temperature in amorphous product. ${ }^{3,7}$ However, the 
57 product temperature profile cannot be directly controlled and depends on the process operating parameters (i.e., shelf temperature, chamber pressure) and on the heat transfer through the container (e.g., vial). ${ }^{4,7,8}$ Knowledge of the heat transfer characteristics of the vial and the uniformity or non uniformity of this property within vial arrangement inside a freezedryer is thus essential to be able to predict final quality of the product batch. Several authors have reported that the heat transfer rate between the shelf and the product is dependent on the vial position on the shelf. ${ }^{4,5,9-12}$ Pikal et al..$^{5}$ showed that the vials located at the periphery of the shelf exhibited sublimation rates $15 \%$ higher than vials located in the center. This phenomenon, referred to as "edge effect", has been ascribed to additional heat transfer by radiation from walls and doors. ${ }^{4,5,8,9,11}$ The higher heat flow rate of these periphery vials could lead to product collapse due to increased product temperatures during the primary drying phase. Furthermore, Pisano et al. ${ }^{10}$ recently observed a normal distribution in the vial heat transfer coefficient evaluated for vials located in the center of the shelf.

The design of the vial also strongly influences the heat transfer efficiency between the shelf and the product. ${ }^{4,5,7,12-15}$ Considering that the vials are placed directly on the shelf, the heat flow transferred to the product can be described by three parallel mechanisms: conduction from the shelf surface to the vial via points of direct contact between the vial bottom and the shelf, conduction through the vapor entrapped in the vial bottom concavity and radiation. $5,8,12$ Heat transfers via contact conduction and conduction through the gas are influenced, respectively, by the dimension of the contact area between the shelf and the vial and the depth of bottom curvature in which the gas is entrapped. ${ }^{5,8,12}$ Several studies ${ }^{13,16,17}$ have demonstrated that the vial bottom curvature limits the heat transfer and, thus, the sublimation flow rate that determines the duration of the primary drying. The concavity of the vial bottom limits the direct surface contact between the vial and the shelf, accounting for most of the resistance to conductive heat transfer. ${ }^{14,16}$ In pharmaceutical freeze-drying conditions, contact 
82 conduction is more efficient than gas conduction, and an increase in the contact area leads to

83 a significant increase in the total heat transfer. ${ }^{5,14}$

84

Our objective was to quantitatively investigate the role of vial geometry distribution on heat transfer heterogeneity and subsequently on product quality by predicting product temperature distribution during the primary drying step induced by variability in vial dimensions. Proposing an approach to understand how vial design and operating conditions interact to influence product quality is completely in the scope of the QbD approach.

In the present study, only vials located in the center of the shelf and surrounded by other vials in the same conditions were considered so as to avoid any heterogeneity due to the additional border heat transfer. The analysis of the heterogeneity was conducted in terms of vial heat transfer coefficient $\left(K_{v}\right)$ distributions. Based on theoretical analysis, ${ }^{5,8,12}$ attention was focused on the role of two vial dimensions, the bottom curvature depth and the contact area between the bottom vial and the shelf. Two shelf temperatures $\left(-40^{\circ} \mathrm{C}\right.$ and $\left.0{ }^{\circ} \mathrm{C}\right)$ and six chamber pressures $(4,6,9,15,40$ and $50 \mathrm{~Pa})$ were tested in two freeze-dryer pilot plants of similar shelf emissivity to assess the impact of these operative parameters on the heat transfer heterogeneity among central vials. Finally, as example of practical application of our work for assessing the pharmaceutical product quality, the impact of the central vial $K_{v}$ variability on product temperature was evaluated. Product temperature distributions for a $5 \%$ sucrose solution were calculated from the simulated $K_{v}$ distributions based on the vial geometry for several operating conditions.

\section{MATERIALS AND METHODS}

\section{Materials}


105 Siliconized glass tubing vials $(3 \mathrm{~mL})$ were provided by Müller + Müller (Holzminden, 106 Germany). These vials are routinely used in commercial manufacturing. Distilled water was 107 used throughout the experiments.

108 Two pilot scale freeze-dryers differing mainly by their size, the type of valve connecting the 109 drying chamber to the condenser and their age were used for this study:

- a LyoVac GT6 (Finn-Aqua Santasalo-Sohlberg SPRL, Brussels, Belgium), referred to as LYO A. It included 5 shelves with an area of $0.14 \mathrm{~m}^{2}$ each, a distance between shelves of 56 $\mathrm{mm}$, a drying chamber volume of $0.061 \mathrm{~m}^{3}$ and a butterfly valve between the chamber and the condenser.

- an Epsilon 2-25D (Martin Christ Gefriertrocknungsanlagen GmbH, Osterode am Harz, Germany), referred to as LYO B. It included 7 shelves with an area of $0.27 \mathrm{~m}^{2}$ each, a distance between shelves of $55 \mathrm{~mm}$, a drying chamber volume of $0.38 \mathrm{~m}^{3}$ and a mushroom valve between the chamber and the condenser.

The pressure in the freeze-dryer chamber was monitored by a capacitive manometer. Since it was not technically possible to install thermocouples in the drying chamber of the two freezedryers, Tempris wireless sensors (IQ Mobil Solution GMbH, Holzkirchen, Germany) were positioned in the bottom center of selected vials (Figure 1) to record ice temperature during the experiments. The obtained signal was used to define the sublimation starting point.

\section{Ice sublimation experiments}

125 All experiments were performed using a $1.8 \mathrm{~mL}$ fill volume of distilled water (filling height: $12611 \mathrm{~mm})$. No stopper was inserted into the vial neck. The middle shelf was fully covered by 127 filled vials for all runs, corresponding to a total of 540 vials in LYO A and 950 vials in LYO B. Bottomless trays were used. 
129 The vials were quickly loaded on the pre-cooled shelf at $-50^{\circ} \mathrm{C}$. The presence of a dry laminar

130 flow in front of the freeze-dryer door made it possible to control the air relative humidity and

131 thus to limit condensation on the shelves. After a freezing step of 2 hours, the pressure was

132 decreased and the shelf temperature was increased by $1{ }^{\circ} \mathrm{C} / \mathrm{min}$. Experiments were carried out 133 at 4, 6, 9, 15, 40 and $50 \mathrm{~Pa}$ with a shelf fluid inlet temperature of $0{ }^{\circ} \mathrm{C}$, and at 4 and $6 \mathrm{~Pa}$ with 134 a shelf fluid inlet temperature of $-40{ }^{\circ} \mathrm{C}$. The run performed at $0{ }^{\circ} \mathrm{C}$ and $6 \mathrm{~Pa}$ was repeated three times. The cycles were run long enough to dry up to $20-25 \%$ of the initial fill volume. Subliming a larger quantity of ice could lead to loss of contact between the vial and the ice, introducing uncertainty in the analysis.

The sublimation rate $\dot{m}$ was measured gravimetrically for each vial and calculated as the mass loss divided by the period of sublimation. A total of 100 vials, placed in the centre of the shelf and surrounded by other vials in the same conditions, were individually weighed before and after the experiment on a precision scale $( \pm 0.001 \mathrm{~g}$; Mettler Toledo, Zaventem, Belgium). Sublimation time was measured from the moment when shelf temperature exceeded product temperature, meaning that there was a net heat flux from the shelf towards the vials. The arrangement of the weighed vials within the shelves is shown in Figure 1 for the two freeze-dryers.

\section{Measurement of emissivity of the vial and of the shelf}

148 Emissivity measurements were performed by Themacs Ingénierie (Champs sur Marne, 149 France). The glass vial emissivity was determined using a Fourier transform infrared spectrophotometer (Frontier, Perkin Elmer, Roissy, France) equipped with a Pike ${ }^{\complement}$ integrant sphere (Pike Technologies, Fitchburg, WI, USA). The measured emissivity varied from 0.78 to 0.80 within the range of temperatures tested (from $-48^{\circ} \mathrm{C}$ to $27^{\circ} \mathrm{C}$ ). Thus, a constant value 
corresponding to the average observed product temperatures (between -48 to $-24{ }^{\circ} \mathrm{C}$ ) was

154

155

156

157 used in the data analysis, as reported in Table 1.

The shelf emissivity was measured using the emissometer EM-2, making it possible an in situ measurement. ${ }^{18}$ The emissivity value of the shelves of LYO B was $0.18 \pm 0.06$ (Table 1). Measurements were carried out on several pilot and production freeze-dryers and shelf emissivity values in the range of $0.18-0.3$ were obtained. Considering the relative standard deviation of the method (0.06), the measured values are in agreement with values reported in literature. $^{5}$

\section{Dimensional analysis of a batch of vials}

The dimensions of 120 vials were precisely measured by the specialized company Precis\&Mans (Le Mans, France) using the micrometer Mitutoyo 3D (Mitutoyo Europe $\mathrm{GmbH}$, Neuss, Germany). The following geometrical parameters were determined with a precision of $0.003 \mathrm{~mm}$ : the inner and outer bottom radius and the maximum bottom curvature depth. These values were used to calculate additional vial dimensions: outer and inner vial bottom area, vial shelf contact area $\left(A_{c}\right)$ (named radius-based contact area in Table 1) and mean bottom curvature depth (l) (Appendix).

Furthermore, the vial-shelf contact area was also estimated using the imprint method proposed by Kuu et al. ${ }^{17}$ and Hibler et al. ${ }^{4}$ The vials were gently placed on an inkpad and then on a sheet of white paper. ImageJ v.1.49 software (National Institutes of Health, Bethesda, MD, USA) was used for the determination of the vial-shelf bottom contact area in pixels from the imprint images. The scale factor of pixels in $\mathrm{mm}^{2}$ was determined by evaluating the number of pixels of a black shape of known area and was equal to $0.0153 \mathrm{~mm}^{2}$ pixel $^{-1}$. The mean value and the relative standard deviation of these geometrical dimensions are reported in Table 1. The two methods used for evaluating the vial-shelf contact area gave similar mean 
values: $16.7 \mathrm{~mm}^{2}$ for the imprint method and $17.8 \mathrm{~mm}^{2}$ for the dimensional analysis. However, the coefficient of variation of these methods appeared different and significantly higher for the imprint method (23.9\% versus $12.0 \%$ for the dimensional analysis). The values of contact area determined using this latter method were selected for the analysis considering that this method better accounts for intimate contact between vial and shelf.

\section{THEORY AND DATA ANALYSIS}

\section{Evaluation of the vial heat transfer coefficient $K_{v}$ based on experimental data}

As widely reported in literature, ${ }^{4,5,8,12}$ the vial heat transfer coefficient $K_{v}$ was calculated using the following equation:

$$
K_{v}=\frac{\dot{Q}}{A_{b}\left(T_{s}-T_{b}\right)}=\frac{\Delta H \dot{m}}{A_{b}\left(T_{s}-T_{b}\right)}
$$

where $\dot{Q}$ is the heat flow received by the vial, $A_{b}$ is the outer vial bottom area, $T_{s}$ is the average temperature between the inlet and outlet shelf fluid temperatures, $T_{b}$ is the bottom product temperature, $\Delta H$ is the latent heat of sublimation and $\dot{m}$ is the sublimation rate.

Since it was not possible to implement thermocouples in the freeze-dryer pilot plant to have a precise measurement of the product temperature, $T_{b}$ was theoretically determined as:

$$
\dot{Q}=\frac{\lambda_{\text {ice }}}{L_{\text {ice }}} A_{\text {in }}\left(T_{b}-T_{i}\right)
$$

Equation 2

where $\lambda_{\text {ice }}$ is the ice thermal conductivity, $A_{\text {in }}$ is the inner bottom area of the vial, $L_{\text {ice }}$ is the ice thickness and $T_{i}$ is the ice-vapor interface temperature. The ice thickness was estimated as 
the mean between the initial and final ice thickness values (calculated using the amounts of initial and sublimed ice).

No stopper and pure water were used in this study in order to assume that the partial pressure of vapor at the sublimation interface was equal to the chamber pressure. The temperature at the ice-vapor interface $T_{i}$ was thus calculated as a function of the interface pressure $P_{i}$ using the Clausius-Clapeyron relation: ${ }^{19}$

$$
T_{i}=\frac{6139.6}{28.8912-\ln \left(P_{i}\right)}
$$

Equation 3

The $T_{b}$ value calculated was compared to the product temperature value given by the Tempris probe and an excellent agreement between experimental and theoretical data was observed.

\section{Theoretical description of the vial heat transfer coefficient $K_{v}$}

The main objective of this work was to quantify the impact of vial dimensions distribution on heat transfer variability and its resulting consequence on product temperature. To this end, the vial heat transfer coefficient need to be theoretically expressed in function of specific vial dimensions.

The vial heat transfer coefficient $K_{v}$ can be described as the sum of three contributions: $:^{5,8,12}$

$$
K_{v}=K_{c}+K_{g}+K_{r}
$$

where $K_{c}$ represents the thermal contact conduction between the shelf and the vial via the direct contact area, $K_{g}$ the thermal conduction through the gas entrapped in the vial bottom curvature and $K_{r}$ the thermal radiation between the vial and the top and bottom shelves. 
227 Heat transfer by thermal contact conduction $K_{c}$

228 The expression of $K_{C}$ has been discussed in the literature by only a few authors. ${ }^{16,17}$ Kuu et 229 al. ${ }^{17}$ proposed an evaluation of this parameter and showed that the larger the contact area is, 230 the larger the value of the contact conduction coefficient will be. Thus, $K_{c}$ can be assumed to 231 be proportional to the contact area $\left(A_{c}\right.$, evaluated by the imprint test method) through an 232 empirical constant $\left(C_{1}\right)$ :

$$
K_{c}=C_{1} A_{c}
$$

Equation 5

235

Heat transfer by conduction through the gas $K_{g}$

237

238

239

240

241

242

$$
K_{g}=\frac{C_{2} P_{C}}{1+\frac{C 2 l}{\lambda_{a m b}} P_{C}}
$$

where $P_{C}$ is the chamber pressure, $\lambda_{a m b}$ is the molecular conductivity of the water vapor at ambient pressure, $l$ is the mean vial bottom curvature depth calculated as reported in the Appendix, and the coefficient $C_{2}$ is equal to:

The coefficient $K_{g}$, representing the contribution of the conduction through the gas in $K_{v}$, can be expressed as: $:^{5,12}$ 
250 at the sublimation interface and the shelf temperature values, ${ }^{12}$ and $\alpha_{c}$ is the accommodation 251 coefficient.

252 Heat transfer by thermal radiation $K_{r}$

253 The heat transfer by radiation between the shelf and the vial $\dot{Q}_{r}^{\text {shelf }}$ can be described by the

254 Stephen-Boltzmann equation: ${ }^{5,8,20}$

255

$$
\dot{Q}_{r}^{\text {shelf }}=A_{r} \mathcal{F} \sigma\left(T_{s}^{4}-T_{b}{ }^{4}\right)
$$

Equation 8

257

where $A_{r}$ is the area exposed to the radiation from the shelves to be considered equal to the vial bottom area $A_{b}, \mathcal{F}$ is the visualization factor and $\sigma$ the Stephan-Boltzman constant. After mathematical rearrangement, Equation 8 can be expressed as:

261

262

$$
\dot{Q}_{r}^{\text {shelf }}=A_{r} \mathcal{F} \sigma\left(T_{s}{ }^{4}-T_{b}{ }^{4}\right)=A_{b} \mathcal{F} \sigma\left(T_{s}+T_{b}\right)\left(T_{s}^{2}+T_{b}^{2}\right)\left(T_{s}-T_{b}\right) \text { Equation } 9
$$

263

Thus, the heat transfer coefficient $K_{r}$ for thermal radiation can be defined as:

$$
K_{r}=\mathcal{F} \sigma\left(T_{s}+T_{b}\right)\left(T_{s}^{2}+T_{b}^{2}\right)
$$

During the process, central vials are affected by two different radiative heat transfer contributions: between (i) the shelf below the vial and the vial bottom, and (ii) the shelf above the vial and the top of the vial. ${ }^{5,8,12}$ Hence, the visualization factor will be the sum of two terms:

$$
\mathcal{F}=\mathcal{F}_{b}+\mathcal{F}_{\text {top }}
$$


275 The visualization factor at the bottom of the vial $\mathcal{F}_{b}$ can be evaluated considering the 276 definition proposed by Bird et $\mathrm{al}^{20}$ and $\mathrm{Pikal}^{8}$ for the heat transfer by radiation between 277 parallel surfaces:

278

$$
\mathcal{F}_{b}=\frac{1}{1+\left(\frac{1}{e_{v}}-1\right)+\left(\frac{1}{e_{s}}-1\right)}
$$

280

281 where $e_{v}$ and $e_{s}$ are the emissivities of the vial and shelf, respectively.

282 Considering vials located in the centre of the shelf and surrounded by other vials in the same conditions, it is possible to assume that (i) the vial area exposed to the top shelf is much smaller than the area of the shelf and (ii) the vial top does not receive radiations from the side walls of the chamber. Thus, the visualization factor between the top of the vials and the shelf $\mathcal{F}_{\text {top }}$ can be estimated equal to the emissivity of the vial: ${ }^{5,8}$

$$
\mathcal{F}_{\text {top }}=e_{v}
$$

Equation 13

289

In agreement with the literature, the visualization factor at the vial top (equal to 0.78; Table

1) is higher than the one at the vial bottom (equal to 0.16 ; Table 1$){ }^{5}$

292

293

Dependence of the vial heat transfer coefficient on vial geometry

294

Equations 4, 5 and 6 were combined to highlight the dependence of $K_{v}$ on the contact area 295 $\left(A_{c}\right)$, and bottom curvature depth $(l)$ :

296

297

$$
K_{v}=C_{1} A_{c}+K_{r}+\frac{C_{2} P_{c}}{1+\frac{l}{\lambda_{a m b}} C_{2} P_{c}}
$$


The term $K_{r}$ was calculated from Equations 10-13 for each experimental condition.

Coefficients $C_{1}$ and $C_{2}$ were determined by fitting Equation 14 in a least-squares sense to experimental $K_{v}$ values determined by the gravimetric method. Calculations were performed with Matlab R2014b software equipped with the Statistics Toolbox (The Mathworks Inc., Natick, MA, USA). The bottom curvature depth $l$ and contact area $A_{c}$ were evaluated from dimensional analysis of the vial and imprint test, respectively.

\section{Calculation of $K_{v}$ distributions based on vial geometry}

Two vial dimensions influence heat transfer: the contact area $\left(A_{c}\right)$ and the mean bottom curvature depth $(l)$. The absence of correlation between the two geometrical dimensions $l$ and $A_{c}$ was verified by calculating the correlation factor together with its statistical significance (p-value $>0.5)$. It was thus possible to independently evaluate the impact of those parameters on $K_{v}$. Using Equation 14, three $K_{v}$ distributions based on vial dimension variations were simulated: (i) curvature-based ( $l$ in Equation 14); (ii) contact area-based ( $A_{c}$ in Equation 14); and (iii) their combination. The curvature-based $K_{v}$ distribution was obtained by evaluating Equation 14 with the 120 measured values of the mean bottom curvature depth $(l)$, while the contact area was maintained constant at its mean value. The contact area-based $K_{v}$ distribution was obtained by evaluating Equation 14 with the 120 measured values of the imprint-based contact area $\left(A_{c}\right)$, whereas the bottom curvature depth was maintained constant at its mean value. Plugging both measured $l$ and $A_{c}$ values into Equation 14 gave the combined contact area and curvature-based $K_{v}$ distribution. The calculation was repeated for all the studied chamber pressures and shelf temperatures. Chi-square goodness-of-fit tests were performed on the simulated $K_{v}$ distributions, establishing that the sample data were consistent with a normal distribution at a 0.05 significance level. 
Product temperature distributions were obtained from the calculated contact area and curvature-based $K_{v}$ distribution. The product temperature was calculated for a $5 \% \mathrm{w} / \mathrm{w}$ sucrose solution, considering a shelf temperature of $-25^{\circ} \mathrm{C}$ and four chamber pressures $(4,6$, 9, $15 \mathrm{~Pa}$ ). Pressure at 40 and $50 \mathrm{~Pa}$ were not considered because the product temperature exceeds the glass transition temperature of the product at such high pressure (i.e., $-32{ }^{\circ} \mathrm{C}$ for a $5 \% \mathrm{w} / \mathrm{w}$ sucrose solution). ${ }^{21}$ In the case of a real product, the mass flow rate can be expressed as reported by Pikal et al. ${ }^{5}$ :

$$
\dot{m}=\frac{\left(P_{i}-P_{c}\right) A_{\text {in }}}{R_{p}}
$$

where $R_{p}$ represents the area-normalized product resistance. The value of $R_{p}$ used for this simulation is reported in Table 1 and was considered for a dried layer thickness of $0.5 \mathrm{~cm} .^{21}$ To simulate the product temperature distribution, the non-linear system composed of Equations 1-3 and 14-15 was solved for each pair of measured $l$ and $A_{c}$ values. Chi-square goodness-of-fit tests were performed on the product temperature distributions, demonstrating that the simulated data were compatible with a normal distribution at a 0.05 significance level.

\section{RESULTS AND DISCUSSION}

\section{Impact of equipment on $K_{v}$}

Vial heat transfer coefficient $K_{v}$ of 100 vials located in the centre of the shelf was experimentally determined for different chamber pressures (4 to $50 \mathrm{~Pa}$ ), shelf temperatures ($40{ }^{\circ} \mathrm{C}$ and $0{ }^{\circ} \mathrm{C}$ ) and freeze-dryers (LYO A and LYO B). Figure 2 illustrates the evolution of the average value of $K_{v}$ with pressure. Equation 14 was fitted with the experimental data and 
the resulting coefficients $C_{1}$ and $C_{2}$ are presented in Table 2 for the data obtained in LYO A, LYO B and their combination. The accommodation coefficient $\alpha_{c}$ was also calculated from Equation 7, considering an average value of the gas temperature obtained under the different operating conditions tested $\left(T_{\text {gas }}=-35{ }^{\circ} \mathrm{C}\right)$. The obtained values of the accommodation coefficient appear to be in agreement with data in literature. ${ }^{8}$

In Table 2, LYO A and LYO B exhibited a similar value of the $C_{1}$ coefficient that is related to the contact area coefficient $K_{c}$ (Equation 5), but distinct values of the $C_{2}$ coefficient that is related to $K_{g}$ (Equation 6). LYO B exhibited a slightly higher accommodation coefficient then LYO A, probably due to a different finish of the freeze-dryer shelf material.

When considering pressure values lower than $10 \mathrm{~Pa}$ (Figure 2), the $K_{v}$ values obtained in the two freeze-dryer appeared similar. This result was confirmed also by Pisano, ${ }^{12}$ who reported no significant difference in $K_{v}$ value of central vials processed in a pilot and manufacturing freeze-dryer at a pressure of $10 \mathrm{~Pa}$. For pressure value higher than $10 \mathrm{~Pa}$, the influence of freeze-dryer configuration became significant with slightly higher values obtained in LYO B (Figure 2). At $50 \mathrm{~Pa}$, the $K_{v}$ value was approximately $8 \%$ higher in LYO B than in LYO A. Considering the different values of $C_{2}$ coefficient, the $K_{v}$ difference between freeze-dryers at high pressure can thus be ascribed to the increased rate of heat transfer through the gas over the total heat flow. However, the physical origin of the differences in the pressure-dependent component of $K_{v}$ remains unclear. Possible hypotheses include: (i) differences in the shelf surface finish that could induce differences in the gas-shelf heat transfer through the accommodation coefficient $^{8}$ (Equation 6-7) as well as (ii) differences in the gas convection conditions, a mechanism responsible for a small part of the pressure-dependent heat

371 transfer. $^{22}$ These results suggest that small differences between devices might become more 372 apparent at high pressures. When considering only vials not exposed to edge effect a cycle designed with low operating pressure (below $10 \mathrm{~Pa}$ ) could therefore be more suitable for safe 
scale-up. However the behavior of the edge vials located at the periphery of the shelf or in contact with metallic band need also to be considered and some elements were recently proposed by Pikal et al. ${ }^{11}$ to investigate the impact of the freeze-dryer configuration.

\section{Impact of chamber pressure and shelf temperature on $K_{v}$}

As reported in the literature and shown in Figure 2, chamber pressure had a strong impact on $K_{v}{ }^{4,5,8,12,13,15}$ The vial heat transfer coefficient increased approximately four times between 4 and $50 \mathrm{~Pa}$. At the vial bottom, the presence of the curvature limits the intimate contact between the shelf and the vial and create an empty space between the shelf and the vial that acts as an insulator. ${ }^{13,16,17}$ At very low pressures typically used in the process, the heat transfer contribution by gas convection is usually neglected, ${ }^{11}$ whereas the contribution of gas conduction has to be considered. This heat transfer mechanism, represented by the coefficient $K_{g}$, is dependent on the chamber pressure and increases when increasing pressure, as shown in Equation $6^{5,8,12,15}$ Figure 3 shows the relative contributions of $K_{c}, K_{r}$ and $K_{g}$ on the total $K_{v}$, calculated using the set $\mathrm{C}$ of the fitting coefficients reported in Table 2. The $K_{c}$ and $K_{r}$ contributions go from about $30 \%$ at $4 \mathrm{~Pa}$ to $10 \%$ at $50 \mathrm{~Pa}$, whereas the $K_{g}$ contribution goes from about $25 \%$ at $4 \mathrm{~Pa}$ to $80 \%$ at $50 \mathrm{~Pa}$.

A moderate effect of shelf temperature on $K_{v}$ was expected theoretically due to $K_{r}$ (Equation 10) and to $K_{g}$ through the gas temperature (Equations 6-7). Figure 4a displays the influence of shelf temperature on $K_{v}$. Differences in $K_{v}$ values due to temperature remained within the standard deviation when considering pressure values lower than $10 \mathrm{~Pa}$ and when the contribution of $K_{g}$ in the total $K_{v}$ is moderate (around $25 \%$, Figure 3 ).

In order to clarify the impact of the shelf temperature, the contributions of the single coefficients $K_{c}, K_{r}$ and $K_{g}$ on $K_{v}$ were calculated for two shelf temperatures $\left(25^{\circ} \mathrm{C}\right.$ and -25 ${ }^{\circ} \mathrm{C}$ ) and three chamber pressures (4, 6 and $50 \mathrm{~Pa}$ ), as show in Figure $4 \mathrm{~b}$. The contact 
conduction coefficient $K_{c}$ does not depend on the shelf temperature (Equation 5) and thus has

400

401

402

403

404

405

406

407

408

409

410

411

412

413

414

415

416

417

418

419

420

421

422

a constant contribution in $K_{v}$ for all the temperatures tested. The radiative coefficient $K_{r}$ depends on the third power of the shelf temperature and increases by about $1 \mathrm{~W} \mathrm{~m}^{-2} \mathrm{~K}^{-1}$ between $-25{ }^{\circ} \mathrm{C}$ and $25{ }^{\circ} \mathrm{C}$ for all pressures considered. The gas conduction coefficient $K_{g}$ depends on the gas temperature and decreases by $0.1-0.2 \mathrm{~W} \mathrm{~m}^{-2} \mathrm{~K}^{-1}$ at low pressures (4-6 Pa) and by $1.1 \mathrm{~W} \mathrm{~m}^{-2} \mathrm{~K}^{-1}$ at $50 \mathrm{~Pa}$, between the two considered values of shelf temperature. When increasing shelf temperature, the increase of $K_{r}$ is partly compensated by the decrease of $K_{g}$. These results confirm that the dependence of $K_{v}$ on the shelf temperature is negligible, especially if compared with the role played by the chamber pressure. Pisano et al. ${ }^{12}$ and Hottot et al. ${ }^{23}$ reported similar $K_{v}$ values for different shelf temperature conditions.

\section{Inter-vial heat transfer heterogeneity and the role of vial dimensions}

Figure 5 presents the experimentally observed distributions of the vial heat transfer coefficient data of central vials at six chamber pressures. Since temperature- and equipmentinduced variations were minor, data obtained in LYO A and B and for the two shelf temperatures were merged. A significant variability in the $K_{v}$ values evaluated for central vials was observed, the standard deviation increasing with pressure from 0.84 to $2.46 \mathrm{~W} \mathrm{~m}^{-2} \mathrm{~K}^{-1}$. The values of standard deviation corresponded to coefficient of variation comprised between 4 and $8 \%$ depending on the operating conditions. The measurement error associated to the determination of $K_{v}$ was evaluated as the sum of the individual measurement accuracy of each parameter entering in the calculation of $K_{v}$ (Equation 1). The measurement uncertainty was estimated to be $\sim 1 \%$. This value is in agreement with the value reported by Pikal et al. $^{5}$, who reported an uncertainty value of $\sim 1.2 \%$. The measurement uncertainty alone did not allow to completely explain the variability of the $K_{v}$ 
data. An external factor responsible for inter-vial heat transfer heterogeneity had thus to be

424

425

426

427

428

429

430

431

432

434

435

436

437

438

439

440

441

442

443

444

445

446

considered.

Attention was focused on the container: the geometrical difference among the vials was considered as a possible source of the heat transfer heterogeneity. This variability in the vial dimensions can be due to production limits and could change as a function of the container model and provider. For the tested vial set, the coefficient of variation was approximately $27.7 \%$ for the mean bottom curvature depth $(l)$ and $23.9 \%$ for the imprint-based contact area $\left(A_{c}\right)$. Hence, the effect of the variability of these geometrical dimensions on $K_{v}$ was evaluated as proposed in the Theory and data analysis section using the set of coefficients $\mathrm{C}$ reported in Table 2.

Figure 6 displays the simulated distributions of $K_{v}$ based on the vial bottom dimensions. These distributions showed a trend and range of $K_{v}$ values similar to the experimental ones. At low pressure, $K_{v}$ variability is almost completely due to the contact area variability. The importance of the contact area on the $K_{v}$ value was also confirmed by Pikal et al. ${ }^{5}$ and Cannon et al. ${ }^{16}$ Regarding the vial bottom curvature, the importance of its variability increased when the pressure rose. This is due to the coefficient $K_{g}$ that plays a major role in the total value of $K_{v}$ at 40 and $50 \mathrm{~Pa}$, as shown in Figure 3. The role of the bottom curvature dimension was previously investigated by Brülls and Radsmuson ${ }^{15}$ and Cannon et al. ${ }^{16}$ Brülls and Radsmuson ${ }^{15}$ have shown that the bottom curvature has an impact on the heat transfer only at chamber pressures higher than $30 \mathrm{~Pa}$. This conclusion was confirmed by Cannon et al. ${ }^{16}$, who found that bottom curvature had little impact when considering low pressure $(<27$ Pa). Our results agree with these conclusions, ${ }^{15,16}$ confirming that the variability of the bottom curvature depth has to be taken into consideration only if cycles at high chamber pressure are performed $(>30 \mathrm{~Pa})$. 
447 Figure 7 displays the coefficient of variation of the experimental and calculated $448 K_{v}$ distributions at different pressures. For the experimental distributions, the coefficient was

449

450

451

452

453

454

455

456

457

458

459

460

461

462

463

464

465

466

467

468

469

470

471

calculated as an average between the LYO A and B datasets. The trend of the observed coefficient of variations for both experimental and simulated $K_{v}$ distributions decreased from approximately $9 \%$ to $4 \%$ when increasing the chamber pressure. The variability of the experimental $K_{v}$ distributions is completely explained by the geometrical variability at low pressures (i.e., 4, $6 \mathrm{~Pa}$ ), whereas at higher pressures, the experimental coefficient of variation appears to be slightly higher than the one calculated based on vial geometry. It is thus possible that other sources of variability should be taken into consideration, for example convection in the drying chamber could play a role if higher pressures are considered. ${ }^{22}$

These considerations can guide the selection of the container as a function of the variability of the vial dimensions. The results obtained show that at low chamber pressure (i.e., 4, 6, 9, $15 \mathrm{~Pa})$, it is important to assess the variability of the contact area between the vial and the shelf, whereas for cycles performed at high pressure (i.e., 40, $50 \mathrm{~Pa}$ ), the variability of the bottom curvature depth becomes a relevant parameter. Consequently, for pharmaceutical processes that are usually carried out at pressures lower than $10 \mathrm{~Pa}$, the contact area needs to be taken into account more than the bottom curvature depth.

Impact of $K_{v}$ heterogeneity on the product temperature distribution within a batch of vials located in the centre of the shelf and not exposed to edge effect

In the case of freeze-drying, product temperature is one of the most important critical quality parameters. During the process, product temperature must be maintained close to a limit value (i.e., glass transition temperature for amorphous products, $T_{g}$ ) in order to optimize the process time but not to exceed it so as to guarantee the visual aspect of the cake and the product quality. 
472 The vial-to-vial heat and mass transfer heterogeneity during the sublimation step causes 473 variability in the product temperature. Considering a constant and fixed value of mass transfer resistance, it would be interesting to estimate the product temperature distribution during the primary drying step resulting only from the variability in vial geometry. Product temperature distributions were thus evaluated considering the contact area and curvaturebased $K_{v}$ distributions. For this analysis, a $5 \%$ w/w sucrose solution was considered, processed at $-25^{\circ} \mathrm{C}$ and four different pressures $(4,6,9$ and $15 \mathrm{~Pa})$. Relevant data concerning product resistance and glass transition temperature $\left(-32^{\circ} \mathrm{C}\right)$ were found in the literature. ${ }^{21}$ As expected, product temperature increased from $4 \mathrm{~Pa}$ to $15 \mathrm{~Pa}$ because of the higher value of the vial heat transfer coefficient and higher ice sublimation temperature.

The variability of the product temperature was estimated to be approximately $0.9{ }^{\circ} \mathrm{C}$ at $15 \mathrm{~Pa}$ and as large as $2.2{ }^{\circ} \mathrm{C}$ at $4 \mathrm{~Pa}$, considering \pm 3 times the standard deviation that includes $99 \%$ of the vials (Figure 8). A practical implication of these results is that, at the low pressures commonly encountered in vaccine freeze-drying, a temperature safety margin of approximately $2{ }^{\circ} \mathrm{C}$ has to be considered with respect to cycles designed on the basis of an average $K_{v}$ value and to vials not exposed to edge effect.

Vials located at the periphery of the shelf (i.e., edge vials) receive additional heating due to the radiation from the chamber walls and the contact with the metallic guardrail. Thus, edge vials present a higher sublimation rate and a higher product temperature respect central vials. ${ }^{5}$

Tang et al. ${ }^{24}$ reports that the temperature difference between edge vials and central vial can be 492 up to $2{ }^{\circ} \mathrm{C}$ at a shelf temperature of $20^{\circ} \mathrm{C}$ and up to $4{ }^{\circ} \mathrm{C}$ at $-30{ }^{\circ} \mathrm{C}$ for a chamber pressure of about $10 \mathrm{~Pa}$. Depending on the operating conditions of the process, the safety product temperature margin resulting from variability in vial dimensions could be in the same order of magnitude than the safety margin imposed by the "edge effect". 


\section{CONCLUSIONS}

498 Implementation of the Quality by Design initiative require a precise definition of the

499

500

501

502

503

504

505

506

507

508

509

510

511

512

513

514

515

516

517

518

519

520 acceptable range for all product and process variables ensuring the fulfillment of the critical quality attributes of the final product. The impact of any variation of these variables on the final quality need to be quantified in advance. In this work, the effect of the variability of geometrical dimensions observed within a batch of vials (i.e., contact area between the shelf and the vial and the mean bottom curvature depth) on product quality was explored. The product quality was evaluating by predicting the product temperature knowing the vial heat transfer coefficient $K_{v}$. An original approach was proposed to calculate $K_{v}$ distribution based on geometrical dimensions when considering a batch of vials located in the center of the shelf not exposed to any edge effect. The impact of freeze-dryer configuration and operating conditions was also considered. When considering low pressure $(<10 \mathrm{~Pa})$, commonly used for freeze-drying biopharmaceuticals, the influence of freeze-dryer configuration and shelf temperature on heat transfer characteristics can be neglected and $K_{v}$ distribution is completely explained by the contact area distribution. Furthermore the variability of vial dimension results in the definition of a product temperature safety margin of $2{ }^{\circ} \mathrm{C}$. However, additional sources of variability need to be included in QbD approach. In particular, a study focused on the variability between edge and central vials and its role in cycle scale-up is presently ongoing.

\section{ACKNOWLEDGMENTS}

The authors would like to thank Benoit Moreau and Yves Mayeresse (GSK Vaccines) for reviewing this manuscript and Vincent Ronsse (technician) and Alain Philippart (operator) (GSK Vaccines) for their help in the data acquisition. 


\section{CONFLICT OF INTEREST}

523 Erwan Bourlés is an employee of the GSK group of companies. Bernadette Scutellà

524 participated in a postgraduate $\mathrm{PhD}$ program at GSK Vaccines. Stephanie Passot, Fernanda

525 Fonseca and Ioan Cristian Trelea report no financial conflicts of interest.

\section{FUNDING}

527 This work was funded by GlaxoSmithKline Biologicals S.A., under a Cooperative Research 528 and Development Agreement with INRA (Institut National de la Recherche Agronomique) 529 via the intermediary of the UMR (Unité Mixte de Recherche) GMPA (Génie et 530 Microbiologie des Procédés Alimentaires) at the INRA Versailles-Grignon research center.

\section{AUTHORS' CONTRIBUTIONS}

533 Bernadette Scutellà, Stephanie Passot, Erwan Bourlés, Fernanda Fonseca and Ioan Cristian 534 Trelea were involved in the conception and design of the study. Bernadette Scutellà and 535 Erwan Bourlès acquired the data. Bernadette Scutellà, Stephanie Passot, Erwan Bourlès, 536 Fernanda Fonseca and Ioan Cristian Trelea analyzed and interpreted the results. All authors 537 were involved in drafting the manuscript or revising it critically for important intellectual 538 content. All authors had full access to the data and approved the manuscript before it was 539 submitted by the corresponding author. 
542 The evaluation of the mean bottom curvature depth $l$ was performed from geometrical 543 considerations on the semi-spherical calotte at the vial bottom, as represented in Figure A.

544 The bottom curvature depth depends on the radius of the vial bottom as follows:

$$
l(r)=R_{c}-a(r)
$$

Equation A1

547

548 where $R_{c}$ is the radius of the calotte and $a(r)$ is the distance between the shelf and the vial

549 bottom, measured normal to the vial bottom:

550

551

$$
a(r)=\sqrt{\left(R_{c}-l_{\max }\right)^{2}+r^{2}}
$$

552

$R_{C}$ can be calculated as a function of the maximum bottom curvature depth $l_{\max }$ and the inner vial bottom radius $R_{i}$ :

555

556

$$
R_{c}^{2}=R_{i}^{2}+\left(R_{c}-l_{\max }\right)^{2}
$$

Equation A3

557

558

559

The area-mean bottom curvature depth can be defined as the integral of $l(r)$ on the calotte, divided by the area:

560

561

$$
l=\frac{1}{A} \int l(r) d A
$$

562

563 The relevant area for heat transfer by gas conduction is:

564 
567 and the area element:

568

571 Combining Equations A1-A6, $l$ was calculated as:

572

573

$$
l=\frac{2}{R_{i}^{2}} \int_{0}^{R_{i}}\left(R_{c}-\sqrt{\left(R_{c}-l_{\max }\right)^{2}+r^{2}}\right) r d r
$$

574

575 


\section{REFERENCES}

577 1. Jennings TA. 1999. Lyophilization: introduction and basic principles. Englewood, CO: $578 \quad$ Interpharm Press.

579 2. Nail SL, Searles JA. 2008. Elements of quality by design in development and scale-up of 580 freeze parenterals. Biopharm Int 21(1):44-52.

581

3. Franks F. 1998. Freeze-drying of bioproducts: putting principles into practice. Eur J

583

584

585

586

587

588

589

590

591

592

593

594

595

596

597

598

599 Pharm Biopharm 45:221-229.

4. Hibler S, Wagner C, Gieseler H. 2012. Vial Freeze-Drying, part 1: New Insights into Heat Transfer Characteristics of Tubing and Molded Vials. J Pharm Sci 101(3):11891201.

5. Pikal MJ, Roy ML, Shah S. 1984. Mass and heat transfer in vial freeze-drying of pharmaceuticals: role of the vial. J Pharm Sci 73(9):1224-1237.

6. Johnson R, Lewis L. 2011. Freeze-drying protein formulations above their collapse temperatures: possible issues and concerns. Am Pharm Rev 14(3):50-54.

7. Hibler S, Gieseler H. 2012. Heat transfer characteristics of current primary packaging systems for pharmaceutical freeze-drying. J Pharm Sci 101(11):4025-4031.

8. Pikal MJ. 2000. Heat and mass transfer in low pressure gases: applications to freeze drying. In Drugs and the Pharmaceutical Sciences 102:611-686.

9. Rambhatla S, Pikal MJ. 2003. Heat and mass transfer scale-up issues during freezedrying, I: atypical radiation and the edge vial effect. Aaps Pharmscitech 4(2):22-31.

10. Pisano R, Fissore D, Barresi AA, Brayard P, Chouvenc P, Woinet B. 2013. Quality by design: optimization of a freeze-drying cycle via design space in case of heterogeneous drying behavior and influence of the freezing protocol. Pharm Dev Technol 18(1):280295. 
600

601

602

603

604

605

606

607

608

609

610

611

612

613

614

615

616

617

618

619

620

621

622

623

624

11. Pikal MJ, Bogner R, Mudhivarthi V, Sharma P, Sane P. 2016. Freeze-Drying Process Development and Scale-Up: Scale-Up of Edge Vial Versus Center Vial Heat Transfer Coefficients, Kv. J Pharm Sci doi:10.1016/j.xphs.2016.07.027.

12. Pisano R, Fissore D, Barresi AA. 2011. Heat Transfer in Freeze-Drying Apparatus. In: Dos Santos Bernardes MA ed., Developments in Heat Transfer 91-114. Rijeka, Croatia: InTech. Available from: http://www.intechopen.com/books/developments-in-heattransfer/heat-transfer-infreeze-drying-apparatus.

13. Nail SL. 1980. The Effect of Chamber Pressure on Heat Transfer in the Freeze Drying of Parenteral Solutions. PDA J Pharm Sci Technol 34(5):358-368.

14. Ybema H, Kolkman-Roodbeen L, te Booy MP, Vromans H. 1995. Vial lyophilization: calculations on rate limitation during primary drying. Pharm Res 12(9):1260-1263.

15. Brülls M, Rasmuson A. 2002. Heat transfer in vial lyophilization. Int J Pharm 246(12):1-16.

16. Cannon A, Shemeley K. 2004. Statistical evaluation of vial design features that influence sublimation rates during primary drying. Pharm Res 21(3):536-542.

17. Kuu WY, Nail SL, Sacha G. 2009. Rapid determination of vial heat transfer parameters using tunable diode laser absorption spectroscopy (TDLAS) in response to step-changes in pressure set-point during freeze-drying. J Pharm Sci 98(3):1136-1154.

18. Monchau JP, Marchetti M, Ibos L, Dumoulin J, Feuillet V, Candau Y. 2014. Infrared Emissivity Measurements of Building and Civil Engineering Materials: A New Device for Measuring Emissivity. Int J Thermophys 35:1817-31.

19. Trelea IC, Passot S, Fonseca F, Marin M. 2007. An Interactive Tool for the Optimization of Freeze-Drying Cycles Based on Quality Criteria. Dry Technol 25(5):741-751.

20. Bird RB, Stewart WE, Lightfoot EN. 1960. Transport phenomena. New York, NY: John Wiley \& Sons. 
625 21. Konstantinidis AK, Kuu W, Otten L, Nail SL, Sever RR. 2011. Controlled nucleation in 626 freeze

627 and primary drying rate. J Pharm Sci 100(8):3453-3470.

628 22. Ganguly A, Nail SL, Alexeenko A. 2013. Experimental Determination of the Key Heat 629 Transfer Mechanisms in Pharmaceutical Freeze-Drying. J Pharm Sci 102(5):1610-1625.

23. Hottot A, Vessot S, Andrieu J. 2005. Determination of mass and heat transfer parameters during freeze-drying cycles of pharmaceutical products. PDA J Pharm Sci Technol 59(2):

632 $138-153$.

633

24. Tang X, Nail SL, Pikal MJ. 2006. Evaluation of manometric temperature measurement, a process analytical technology tool for freeze-drying: Part I, product temperature measurement. AAPS PharmSciTech 7(1):E95-E103.

636

637 

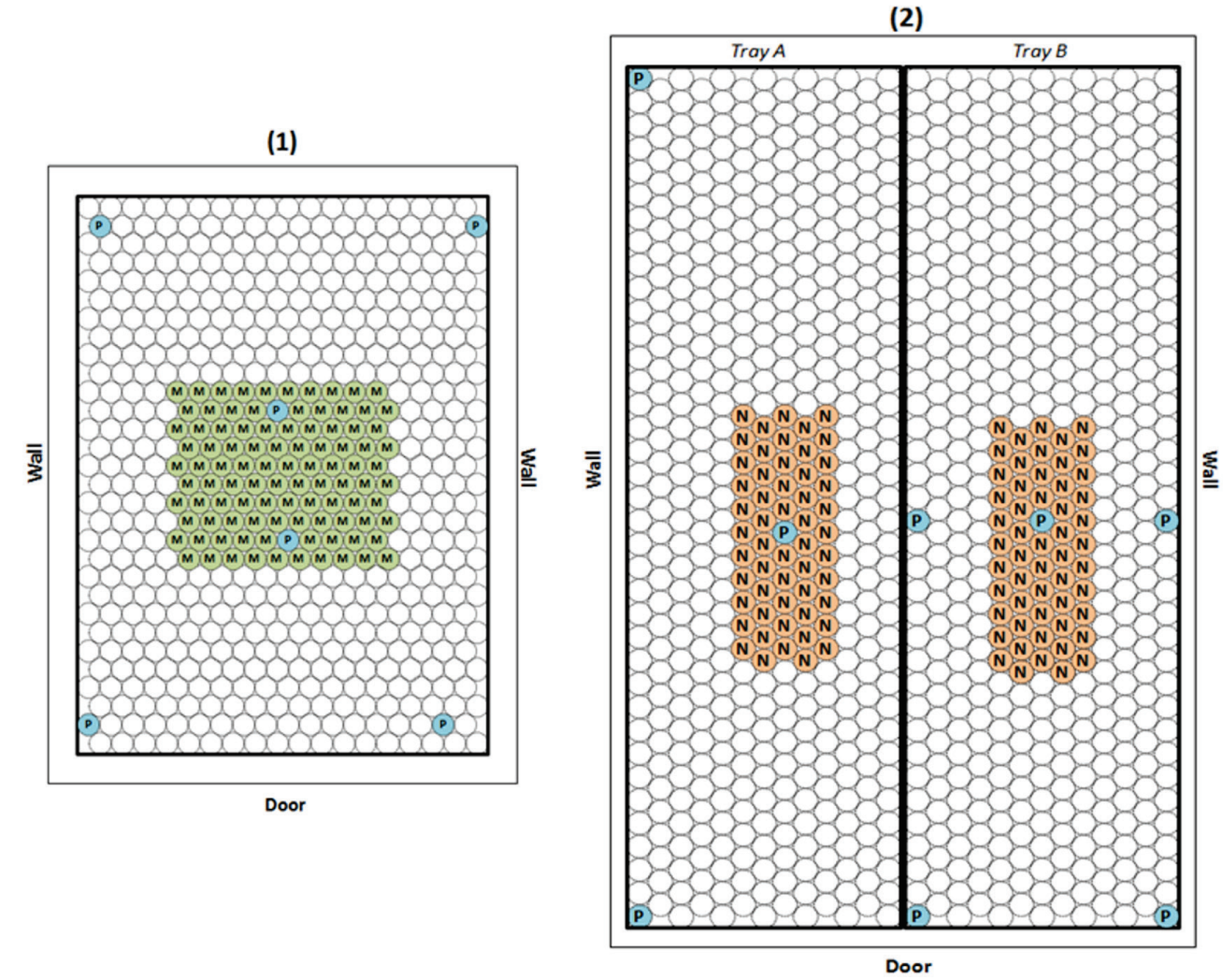

639

640 Figure 1. Vial arrangements in (1) LYO A and (2) LYO B. Gravimetrically-analyzed vials 641 are marked with the letters $\mathrm{M}$ and $\mathrm{N}$ for LYO A and B, respectively. Vials in which wireless 642 temperature probes were located are marked with the letter P. All vials were filled with 1.8 $643 \mathrm{~mL}$ of pure water.

644

645

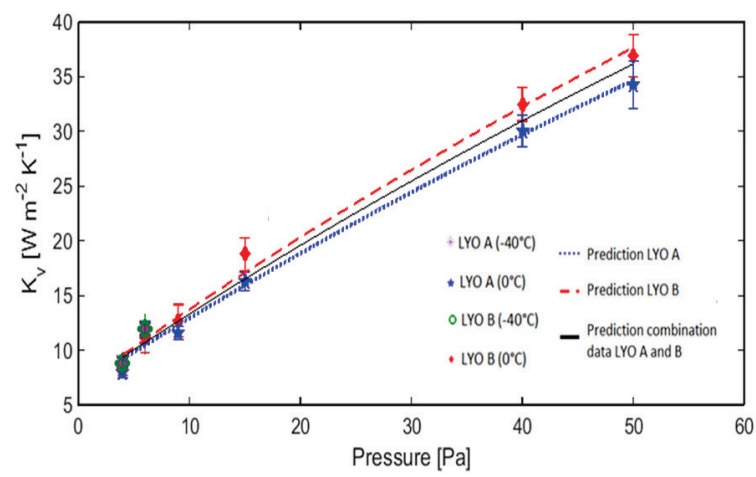


646 Figure 2. Vial heat transfer coefficient $\left(K_{v}\right)$ values vs. chamber pressure $\left(P_{c}\right)$. The markers 647 refer to the $K_{v}$ average values measured in $\mathrm{LYO} \mathrm{A}$ and $\mathrm{B}$ at $-40^{\circ} \mathrm{C}$ and $0^{\circ} \mathrm{C}$. The lines 648 correspond to the values calculated with Equation 14 with the data obtained from LYO A, B 649 and their combination. Error bars represent standard deviations.

650

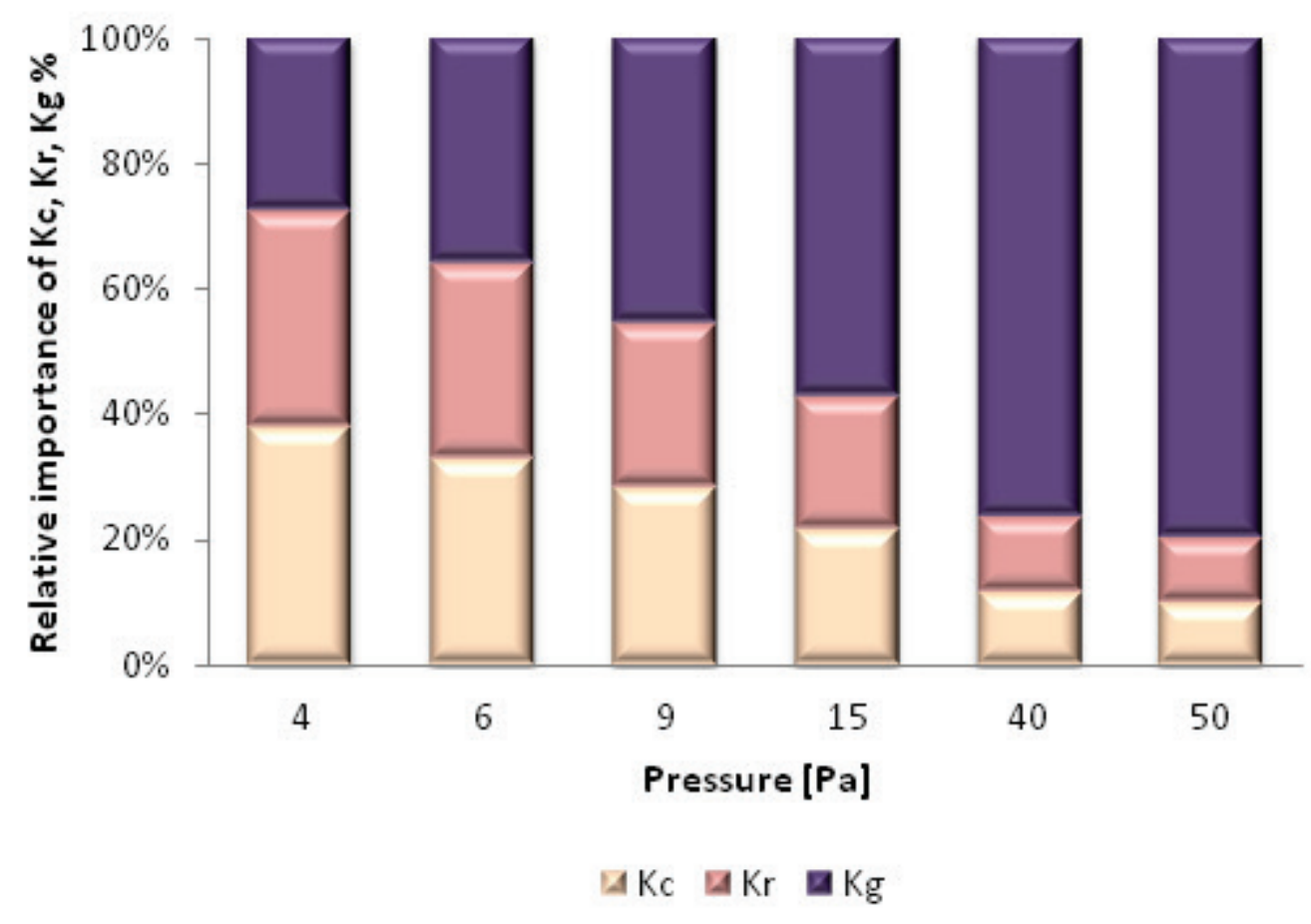

651

652 Figure 3. Relative importance of the heat transfer coefficients by contact conduction $\left(K_{c}\right)$, radiation $\left(K_{r}\right)$ and conduction through the gas $\left(K_{g}\right)$ as percentages of the total heat transfer 654 coefficients $\left(K_{v}\right)$. Average values of the contact area $\left(A_{c}\right)$ and mean bottom curvature depth 655 (l) were considered in this calculation. The set of coefficients $\mathrm{C}$ (Table 2) was used to 656 evaluate $K_{c}$ and $K_{g}$.

657 
(a)

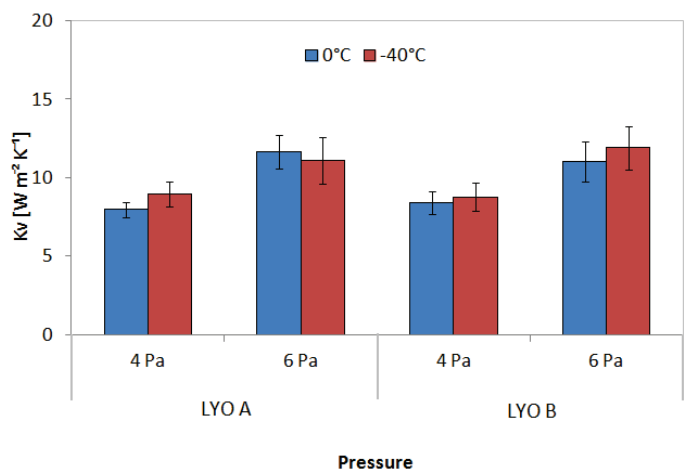

(b)

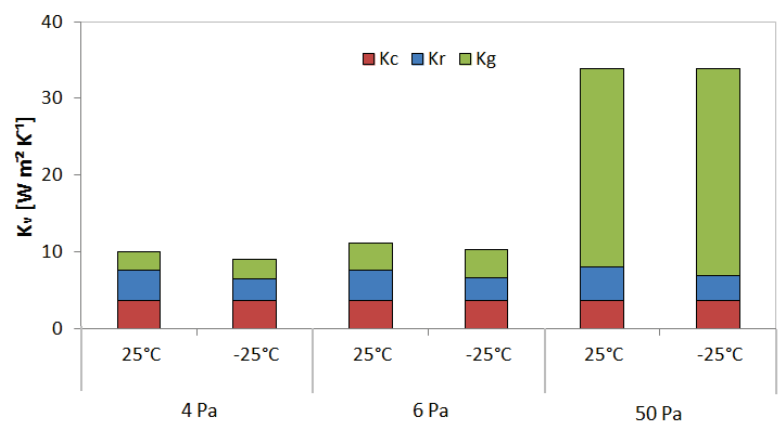

Shelf Temperature and Chamber Pressure
658

659 Figure 4. Influence of the shelf temperature on the vial heat transfer coefficients $K_{v} . K_{v}$ 660

661

662

663

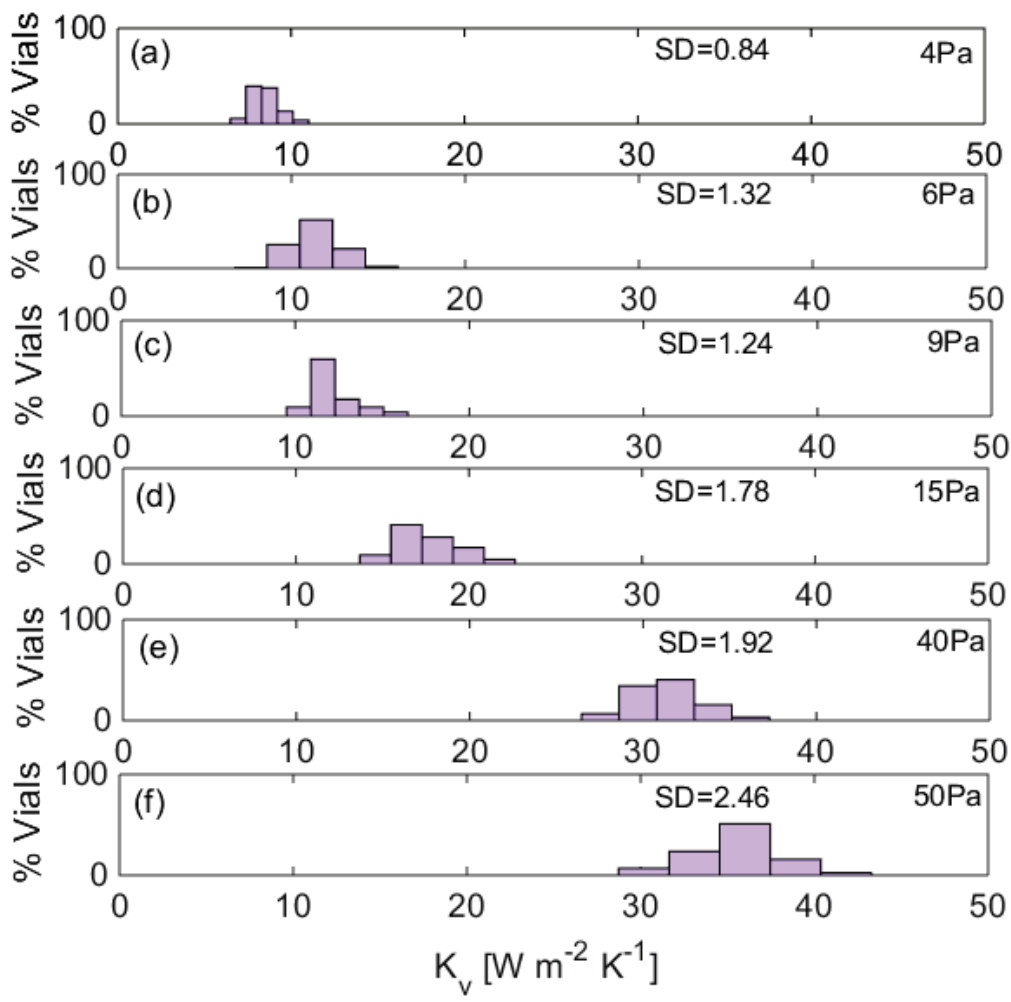

665 Figure 5. Experimentally-measured distribution of the vial heat transfer coefficients at $4 \mathrm{~Pa}$ 666 (a), $6 \mathrm{~Pa}(\mathrm{~b}), 9 \mathrm{~Pa}(\mathrm{c}), 15 \mathrm{~Pa}(\mathrm{~d}), 40 \mathrm{~Pa}(\mathrm{e})$ and $50 \mathrm{~Pa}(\mathrm{f})$. Data of LYO A and LYO B at 667 different shelf temperatures $\left(0^{\circ} \mathrm{C}\right.$ and $\left.-40^{\circ} \mathrm{C}\right)$ were combined. 

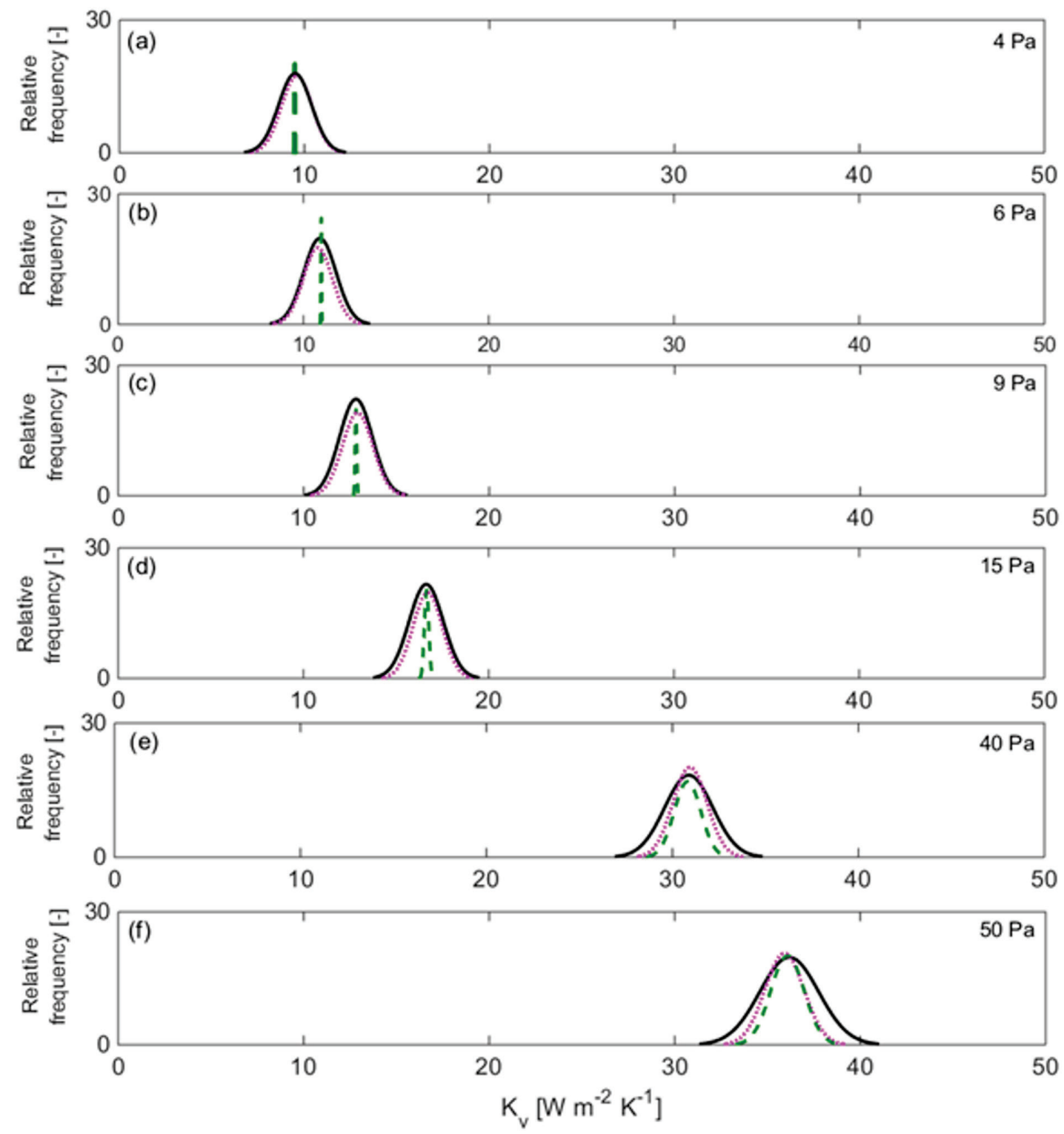

669

670 Figure 6. Calculated $K_{v}$ normal distributions: curvature-based (dashed green line -- ),

671 contact area-based (dotted red line - - -) and combined curvature and contact area-based

672 (solid black line -) at $4 \mathrm{~Pa}(\mathrm{a}), 6 \mathrm{~Pa}$ (b), (c) $9 \mathrm{~Pa}$ (c), $15 \mathrm{~Pa}$ (d), $40 \mathrm{~Pa}$ (e) and $50 \mathrm{~Pa}$ (f).

673 


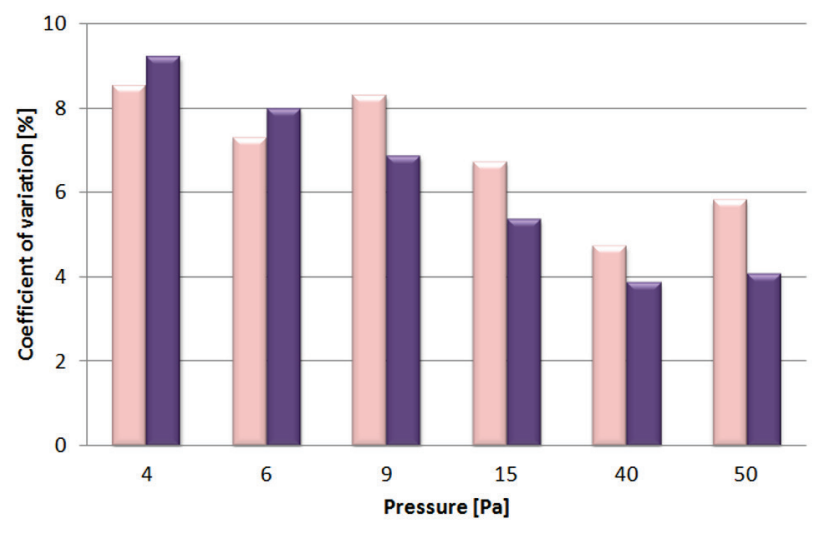

675 Figure 7. Coefficients of variation of experimentally-measured $K_{v}$ distribution (LYO A and

$676 \mathrm{~B}$; light bars) and calculated (combined contact area and curvature-based) $K_{v}$ distribution 677 (dark bars) and at different pressures.

678
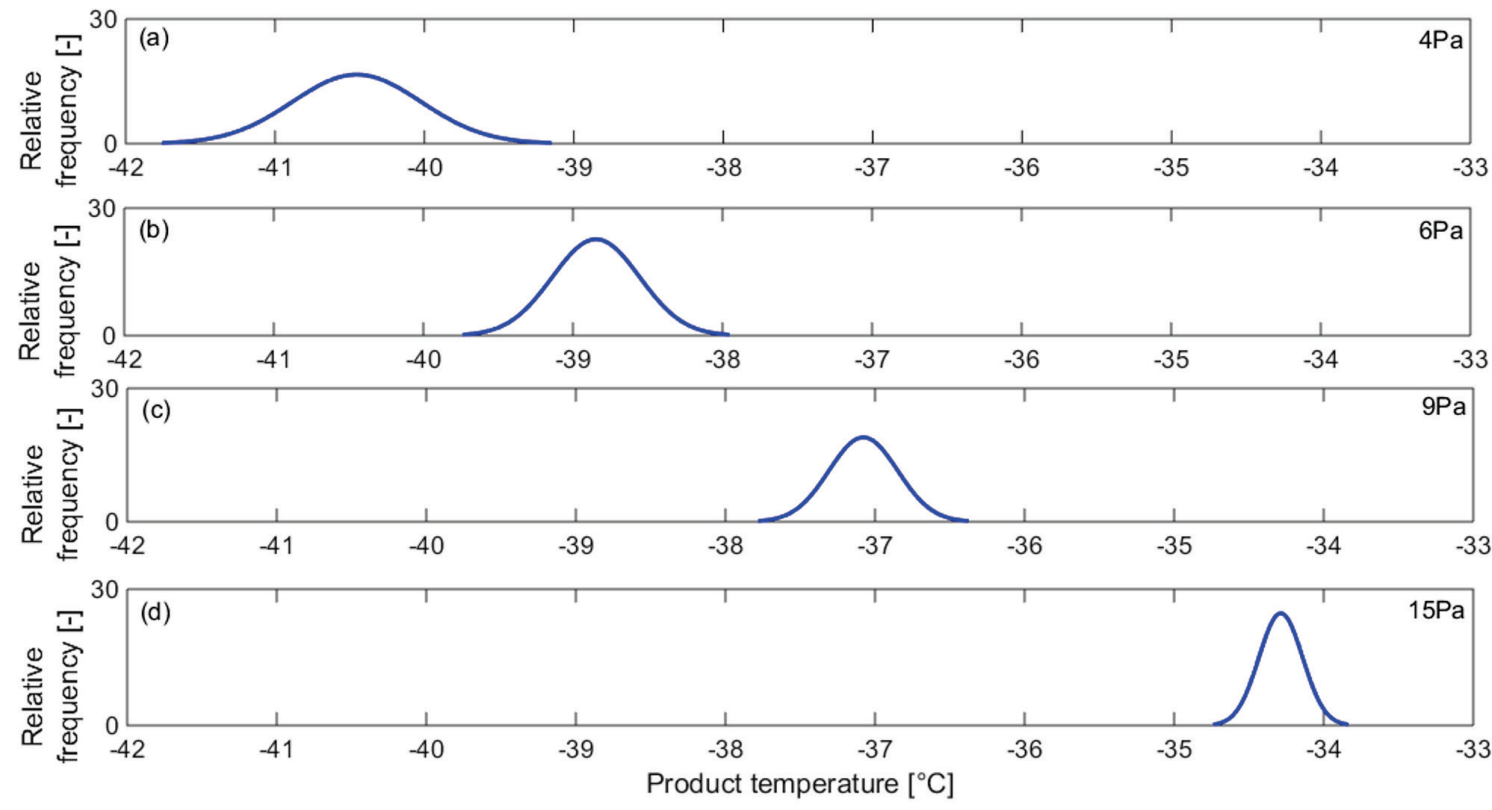

679

680 Figure 8. Product temperature distributions obtained from the contact area and curvature-

681 based distribution for a $5 \% \mathrm{w} / \mathrm{w}$ sucrose solution processed at a shelf temperature of $-25{ }^{\circ} \mathrm{C}$ and four chamber pressures: (a) $4 \mathrm{~Pa}$, (b) $6 \mathrm{~Pa}$, (c) $9 \mathrm{~Pa}$ and (d) $15 \mathrm{~Pa}$. 
(1)

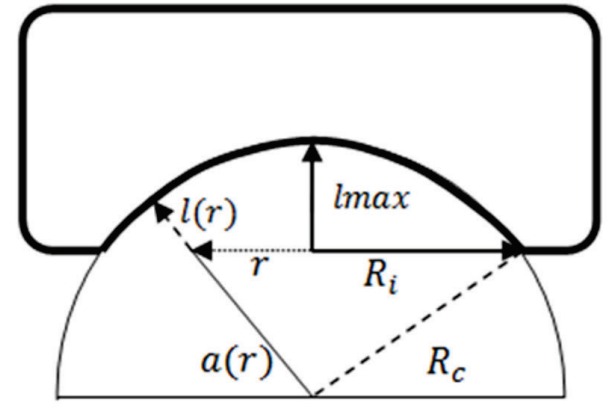

(2)

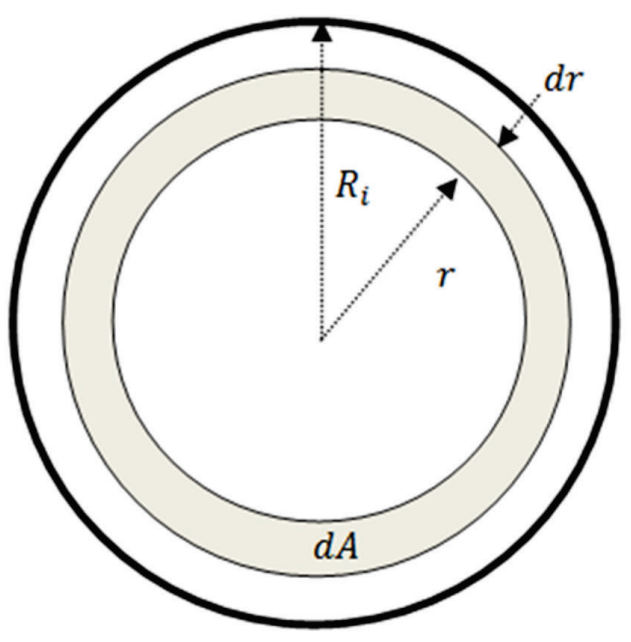

684

Figure A. Side (1) and top (2) view of the vial bottom represented as a semi-spherical calotte.

686

687

688 